\title{
Cine-CMR quantified left atrial diameter - a simple index of left atrial remodeling that closely parallels chamber area and stratifies longitudinal atrial arrhythmic risk
}

\author{
Jiwon Kim²*, Sergey Gurevich', Jonathan D Kochav', Maya M Petashnick', Anika Afroz', Peter M Okin', \\ Agnes S Kim', Richard B Devereux', Jonathan W Weinsaft ${ }^{1,2}$
}

From 17th Annual SCMR Scientific Sessions

New Orleans, LA, USA. 16-19 January 2014

\section{Background}

Cine cardiac magnetic resonance (cine-CMR) provides excellent endocardial delineation, enabling accurate quantification of left atrial (LA) chamber size. Relative utility of cine-CMR linear dimensions and area-based indices for prediction of LA-associated arrhythmias is unknown.

\section{Methods}

The study comprised patients with coronary artery disease (CAD) included in a multimodality registry. CineCMR (1.5T) was performed using a standard 2-dimensional steady state free precession (SSFP) pulse sequence (typical TR $3.5 \mathrm{msec}$, TE $1.6 \mathrm{msec}$, flip angle $60^{\circ}$, temporal resolution $30-50 \mathrm{msec}$ ). Cine-CMR evidenced mitral regurgitation (MR) severity was graded in accordance with established conventions based on size of MR associated inter-voxel dephasing of the regurgitant jet. LA size was measured on cine-CMR at atrial end-diastole using two established methods: [1] linear diameter (measured in 3-chamber long axis orientation), [2] area (planimetered in 4-chamber long axis orientation), with both indices indexed to body surface area. Clinical follow-up was performed via medical record review, with atrial fibrillation (AF) or flutter (AFl) verified based on physician documentation.

${ }^{2}$ Medicine, Memorial Sloan Kettering Cancer Center, New York, New York USA

Full list of author information is available at the end of the article

\section{Results}

336 patients with CAD were studied $(60 \pm 12$ yo, $79 \%$ M, 34\% DM, 58\% HTN); LA diameter (mean $2 \pm 0.4$ $\mathrm{cm} / \mathrm{m} 2)$ and area $(12 \pm 3 \mathrm{~cm} 2 / \mathrm{m} 2)$ yielded similar prevalence of chamber dilation $(20 \%$ vs. $21 \%, \mathrm{p}=0.76)$ assigned using established cine-CMR population-based cutoffs. LA indices correlated highly $(\mathrm{r}=0.74, \mathrm{p}<0.001$; Figure 1), with similar magnitude of correlation among subgroups at risk for LA remodeling, such as patients

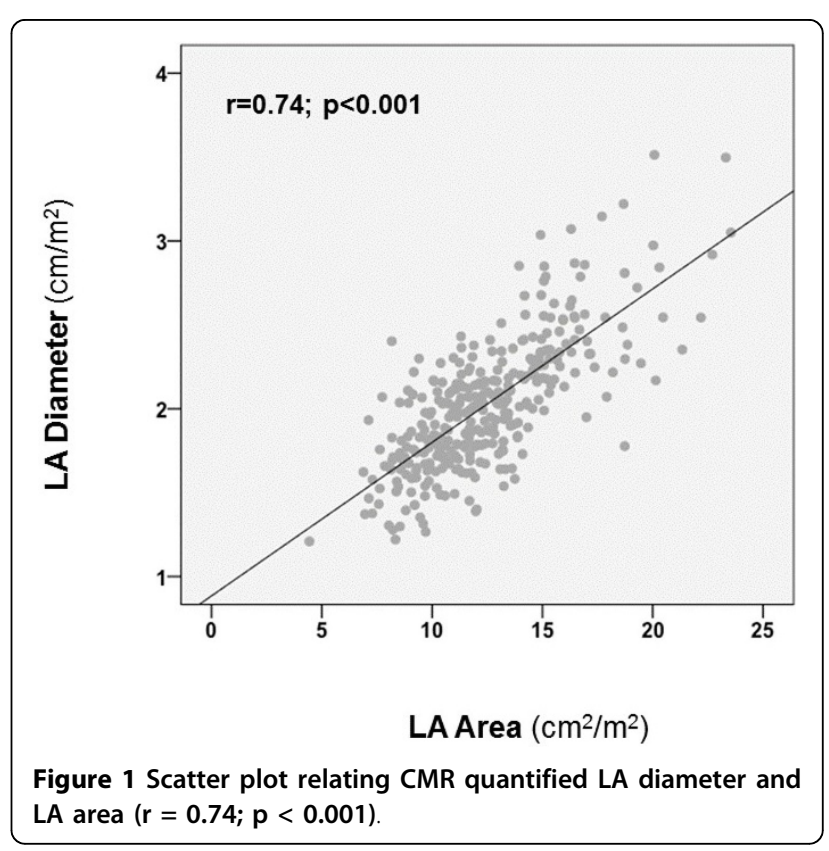




\section{$2 A$.}

\section{Left Atrial Diameter}

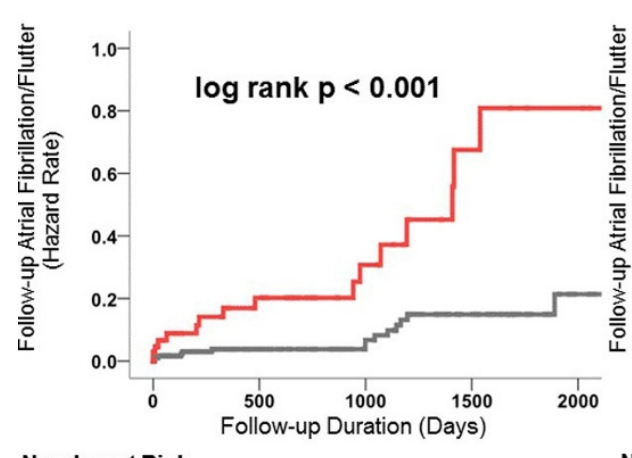

Number at Risk

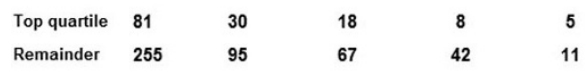

$2 B$.

\section{Left Atrial Area}

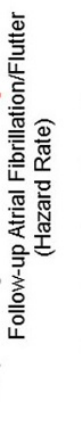

1.0- $\quad \log$ rank $p<0.001$

Number at Risk

Top quartile 79

\subsection{1}

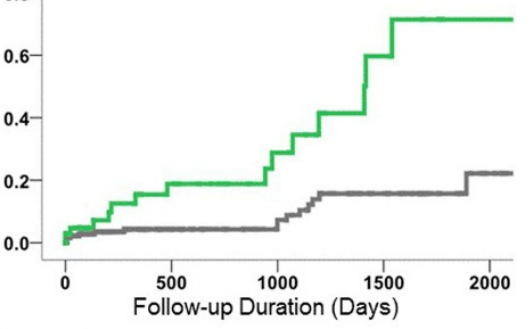

Remainder 257

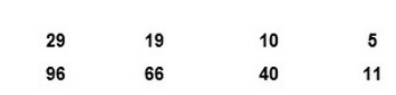

\section{- Top LAArea Quartile
- Remainder of Population}

Figure 2 Kaplan-Meier plots relating baseline LA diameter (2A) and LA area (2B) to follow-up risk for AF/AFI. Note that both LA diameter and LA area demonstrate increased risk for AF/AFI among patients in the highest quartile of LA remodeling.

with HTN $(\mathrm{r}=0.74, \mathrm{p}<0.001)$ and DM $(\mathrm{r}=0.77, \mathrm{p}<$ 0.001). Severe MR was 9-fold more common among patients in the top quartile of LA diameter compared to the remainder of the population ( $19 \%$ vs. $2 \%, \mathrm{p}<0.001)$, with similar results when prevalence of severe MR was compared among patients stratified by LA area (17\% vs. $3 \%, \mathrm{p}<0.001$ ). Clinical follow-up (minimum 60 days) was available in $46 \%$ of the study population ( $n=168$ ). During mean follow-up of $1.5 \pm 1.9$ years, 31 patients (18\%) developed AF/AFl: Cine-CMR quantified LA dimensions stratified arrhythmic risk, with a 5-fold increase in relative risk for $\mathrm{AF} / \mathrm{Fl}$ among patients in the highest LA diameter quartile (HR 5.1, CI 1.5 - 17.1, p < 0.05 ), and a 3 -fold increase for those in the highest quartile of LA area (HR 3.4, CI 1.1 to $10.6, \mathrm{p}<0.05$ ) compared to the remainder of the population (Figure 2).

\section{Conclusions}

Cine-CMR quantified LA diameter provides a simple measure of atrial remodeling that correlates well with LA area, yielding similar predictive value for stratifying $\mathrm{MR}$ as well as longitudinal risk for atrial arrhythmias.

\section{Funding}

National Institutes of Health (K23 HL102249-01).

\section{Authors' details}

${ }^{1}$ Medicine, Weill Cornell Medical College, New York, New York, USA ${ }^{2}$ Medicine, Memorial Sloan Kettering Cancer Center, New York, New York, USA.
Published: 16 January 2014

doi:10.1186/1532-429X-16-S1-P225

Cite this article as: Kim et al:: Cine-CMR quantified left atrial diameter a simple index of left atrial remodeling that closely parallels chamber area and stratifies longitudinal atrial arrhythmic risk. Journal of Cardiovascular Magnetic Resonance 2014 16(Suppl 1):P225.
Submit your next manuscript to BioMed Central and take full advantage of:

- Convenient online submission

- Thorough peer review

- No space constraints or color figure charges

- Immediate publication on acceptance

- Inclusion in PubMed, CAS, Scopus and Google Scholar

- Research which is freely available for redistribution 